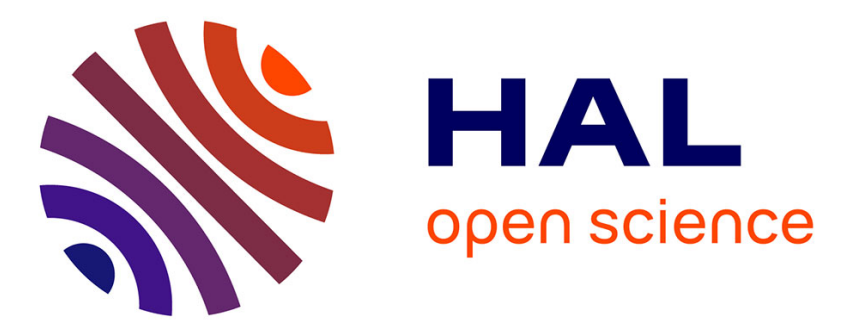

\title{
Atmospheric Circulations Induced by a Mid latitude SST Front: A GCM Study
}

Sidonie Brachet, Francis Codron, Yizhak Feliks, Michael Ghil, Hervé Le Treut, Eric Simonnet

\section{To cite this version:}

Sidonie Brachet, Francis Codron, Yizhak Feliks, Michael Ghil, Hervé Le Treut, et al.. Atmospheric Circulations Induced by a Mid latitude SST Front: A GCM Study. Journal of Climate, 2012, 25 (6), pp.1847-1853. 10.1175/JCLI-D-11-00329.1 • hal-01111219

\section{HAL Id: hal-01111219 https://hal.science/hal-01111219}

Submitted on 29 Jan 2015

HAL is a multi-disciplinary open access archive for the deposit and dissemination of scientific research documents, whether they are published or not. The documents may come from teaching and research institutions in France or abroad, or from public or private research centers.
L'archive ouverte pluridisciplinaire HAL, est destinée au dépôt et à la diffusion de documents scientifiques de niveau recherche, publiés ou non, émanant des établissements d'enseignement et de recherche français ou étrangers, des laboratoires publics ou privés. 


\title{
Atmospheric Circulations Induced by a Midlatitude SST Front: A GCM Study
}

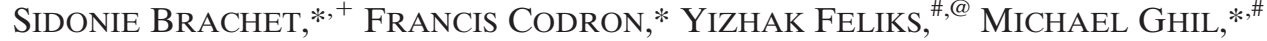 \\ HERVÉ LE TREUT,* AND ERIC SIMONNET ${ }^{\&}$ \\ * Laboratoire de Météorologie Dynamique, IPSL, CNRS, Ecole Normale Supérieure, Université Pierre et \\ Marie Curie, Paris, France \\ + IFREMER, Laboratoire d'Océanographie Spatiale, Plouzané, France \\ \# Atmospheric and Oceanic Sciences Department, and Institute of Geophysics and Planetary Physics, University of \\ California, Los Angeles, Los Angeles, California \\ @ Department of Mathematics, Israel Institute of Biological Research, Nes-Ziona, Israel \\ \& Institut Non-Linéaire de Nice, CNRS, and Université de Nice Sophia-Antipolis, Nice, France
}

(Manuscript received 2 June 2011, in final form 6 October 2011)

\begin{abstract}
The atmospheric effects of sea surface temperature (SST) anomalies over and near western boundary currents are a matter of renewed interest. The general circulation model (GCM) of the Laboratoire de Météorologie Dynamique (LMD-Z) has a zooming capability that allows a regionally increased resolution. This GCM is used to analyze the impact of a sharp SST front in the North Atlantic Ocean: two simulations are compared, one with climatological SSTs and the other with an enhanced Gulf Stream front. The results corroborate the theory developed previously by the present team to explain the impact of oceanic fronts. In this theory, the vertical velocity at the top of the atmospheric boundary layer has two components: mechanical and thermal. It is the latter that is dominant in the tropics, while in midlatitudes both play a role in determining the wind convergence above the boundary layer. The strengthened SST front does generate the previously predicted stronger ascent above the warmer water south of the front and stronger descent above the colder waters to the north. In the GCM simulations, the ascent over the warm anomalies is deeper and more intense than the descent.
\end{abstract}

\section{Introduction and motivation}

Western boundary currents, including the Gulf Stream and Kuroshio, play a unique role in midlatitude oceanatmosphere interactions because of the magnitude of local surface heat fluxes, and because local SST variability is mostly driven by ocean dynamics (Kwon et al. 2010). Recent satellite observations show that small-scale SST features-such as meanders and fronts-have a strong impact on air-sea heat and momentum fluxes (Kelly et al. 2010). In particular, warm SSTs tend to be correlated at small spatial scales with higher surface wind speeds (Small et al. 2008; Bryan et al. 2010).

Several regional modeling studies have shown that SST fronts impact the marine atmospheric boundary layer (MABL) (Warner et al. 1990). Small et al. (2008) reviewed

Corresponding author address: Francis Codron, Laboratoire de Météorologie Dynamique, Université Pierre et Marie Curie, Case 99, 75005 Paris, France.

E-mail: fcodron@lmd.jussieu.fr two mechanisms that may drive surface wind anomalies: (i) changes in MABL stability (Wallace et al. 1989), with a more stable atmosphere leading to higher vertical shear and lower surface wind speed; and (ii) anomalies in the surface pressure gradient. O'Neill et al. (2010) used a regional model to show that both mechanisms help drive the surface wind, but their impacts differ over the height of the MABL - changes in vertical mixing redistribute momentum but have little impact on the vertically averaged wind.

Feliks et al. (2004, 2007) [FGS(a,b) hereafter] formulated an analytic relationship between the SST and the pressure gradient by using an idealized, linear MABL model. Atmospheric temperature anomalies in this model are restricted to the mixed layer and follow the underlying SST as in the tropical model of Lindzen and Nigam (1987). The FGS model includes, though, the Coriolis force, as well as the impact of the large-scale geostrophic flow, which matter in the midlatitudes.

After a vertical integration of the modified Ekman spiral equations, FGS(a) obtained a vertical wind velocity $w$ at the top $H_{e}$ of the MABL given by 


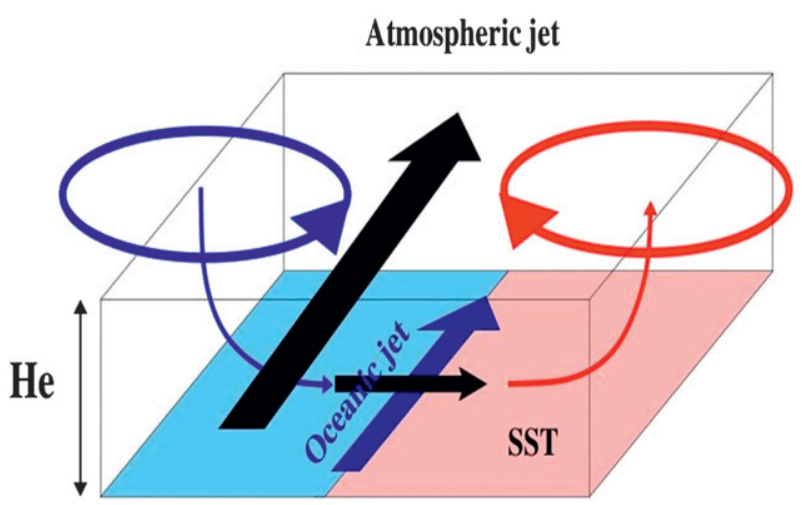

FIG. 1. Schematic illustration of the FGS mechanism [FGS(a,b)] of SST front impacts. The sharp SST gradient forces a mesoscale cross-front circulation. The resulting vertical velocity at the top of the MABL induces vorticity anomalies in the free troposphere and a jet parallel to the surface isotherms. The vertical velocity at the top of the MABL has a thermal component, similar to that of Lindzen and Nigam (1987) in the tropics, and a mechanical one, which is substantial in the midlatitudes; see text for details.

$$
w\left(H_{e}\right)=-\int_{0}^{H_{e}}\left(\frac{\partial u}{\partial x}+\frac{\partial v}{\partial y}\right) d z=\gamma \nabla^{2} \psi-\alpha \nabla^{2} T ;
$$

here $T=T(x, y)$ is the SST field, $(u, v)$ are the horizontal wind components in the MABL, and $\psi$ is the horizontal streamfunction of the large-scale flow above the MABL, while $\alpha$ and $\gamma$ are positive constants. The first term on the right-hand side of Eq. (1) is called the mechanical component and it represents Ekman pumping due to surface friction. The second term is called the thermal component and it accounts for the impact of MABL temperature anomalies on the surface pressure, with warmer temperatures leading to lower surface pressure through hydrostatic balance.

The thermal component of $w\left(H_{e}\right)$ in Eq. (1) implies that, over cold SSTs, air descends and will force a cyclonic flow in the free atmosphere, while over warm SSTs air ascends and the free-atmospheric flow will be anticyclonic. These two thermally induced vortices then spin up a jet in the free atmosphere parallel to the front, as shown in Fig. 1. This behavior was reproduced in idealized barotropic [FGS(a)] and baroclinic [FGS(b)] models driven by vertical velocities from Eq. (1).

Indeed, when using observed high-resolution SSTs as an input, Feliks et al. (2011) obtained realistic interannual atmospheric variability. Nakamura and Yamane (2009) also observed links between local SST anomalies and the large-scale atmospheric circulation. FGS(a,b) found that the SST front impacts on the free atmosphere only occurred when the atmospheric models had a sufficiently high horizontal resolution of at least $50 \mathrm{~km}$; they disappeared at the lower resolutions typically used in current Intergovernmental Panel on Climate Change (IPCC)-class GCMs.

Using a much-higher-resolution GCM, Minobe et al. (2008) studied the atmospheric response to either realistic or strongly smoothed SSTs in the Gulf Stream region. They obtained an intensification of precipitation along the front and upward vertical velocity anomalies penetrating deep into the troposphere. In a similar experiment in the Kuroshio region, Taguchi et al. (2009) showed that the kinetic energy of baroclinic eddies was locally enhanced in the presence of a strong SST front.

The goal of this paper is to reexamine the regional impact of SST fronts on the atmosphere and compare it with proposed theoretical mechanisms by using an IPCCclass atmospheric GCM with a locally high resolution. The numerical experiments are described in section 2 . Section 3 presents the circulation changes forced by a local strengthening of an SST front. Section 4 then compares the drivers of the atmospheric response with the FGS theory.

\section{Experimental setup}

\section{a. The atmospheric GCM}

We use the Laboratoire de Météorologie Dynamique general circulation model (LMD-Z) (Hourdin et al. 2006) - a gridpoint GCM capable of variable horizontal resolution. The resolution here is enhanced to $0.5^{\circ} \times 0.5^{\circ}$ inside a zoomed area over the Gulf Stream region that is centered at $40^{\circ} \mathrm{N}, 65^{\circ} \mathrm{W}$ and covers $20^{\circ}$ of latitude by $40^{\circ}$ of longitude. The resolution then decreases gradually to $3^{\circ} \times 3^{\circ}$ outside the zoomed area. There are 120 points in longitude by 91 in latitude, with 19 hybrid sigma-pressure levels in the vertical.

\section{b. Numerical experiment design}

We study the results from two simulations, and call the first one CTL (for "control run"); it uses climatological, high-resolution SSTs. In the second one, called STR (for "strong front"), the SST front along the Gulf Stream has been reinforced by an idealized, strong, and narrow SST anomaly dipole centered at $40^{\circ} \mathrm{N}, 60^{\circ} \mathrm{W}$; its width is $5^{\circ}$ and its spatial pattern is given by

$$
T(\xi, \eta)=A \cos (\xi) \sin (\eta) .
$$

Here $(\xi, \eta)$ are the along- and cross-front coordinates, rotated counterclockwise by $12^{\circ}$ with respect to $(x, y)$, and $A=5 \mathrm{~K}$ is an amplitude normalization. The resulting anomalies have zero spatial average and are shown in Fig. 2a. Both simulations were run for 870 days in a perpetual-date mode corresponding to 15 February: 
(a) SST

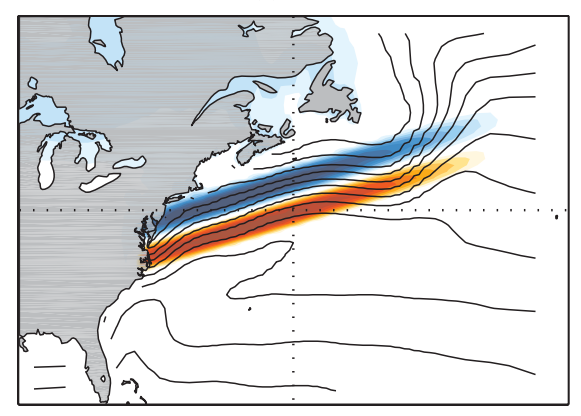

(c) Sensible heat flux

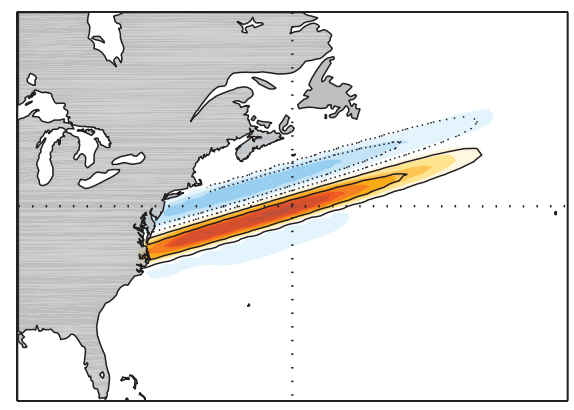

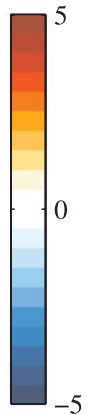
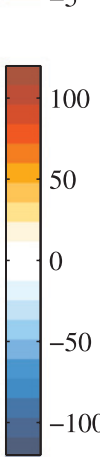

(b) Precipitation

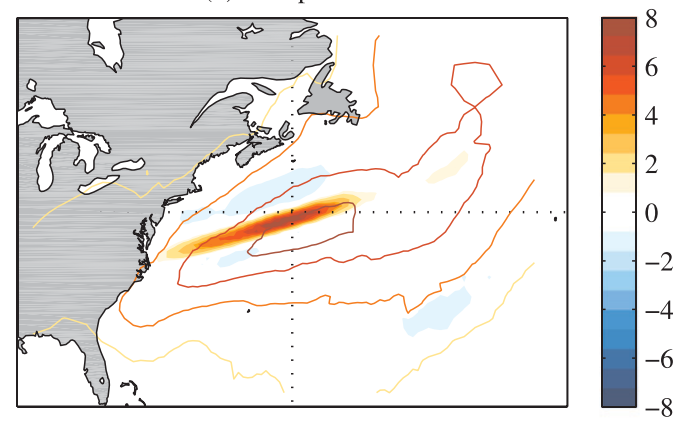

(d) Latent heat flux

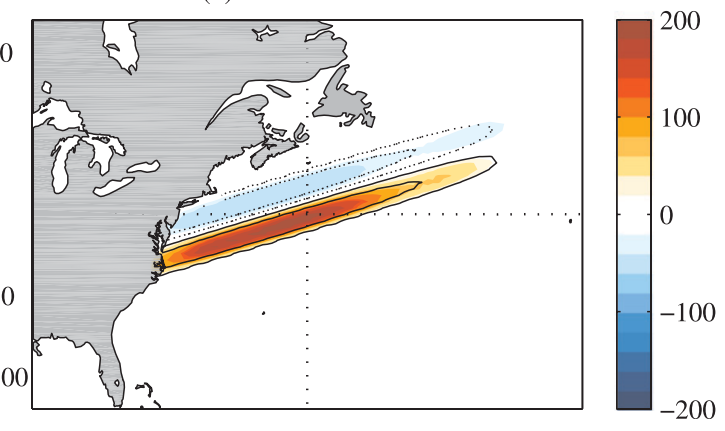

FIG. 2. Difference fields STR - CTL over the western North Atlantic Ocean $\left(30^{\circ}-50^{\circ} \mathrm{N}, 75^{\circ}-55^{\circ} \mathrm{W}\right)$. Both the CTL and STR experiments have a locally high resolution over the Gulf Stream region, but CTL has climatological SSTs while the STR experiment has an enhanced SST front; see text for details. Positive anomalies are in red, and negative ones are in blue. (a) SST field, with mean SST contours in CTL every $2 \mathrm{~K}$; (b) precipitation ( $\mathrm{mm} \mathrm{day}^{-1}$ ), with mean CTL contours every $2 \mathrm{~mm} \mathrm{day}^{-1}$; (c) sensible heat flux ( $\mathrm{W} \mathrm{m}^{-2}$; positive toward the atmosphere), with the contours of the SST difference field from (a) superimposed in color; and (d) latent heat flux; units are as in (c).

this choice gives a stable climate that resembles the observed winter climatology and does not give rise to any climate drift.

\section{Sensitivity to frontal strength}

\section{a. Surface fields}

The mean differences in surface heat fluxes between the STR and CTL simulations are shown in Figs. 2c,d. The pattern of surface flux anomalies follows closely the SST anomaly pattern: heat fluxes toward the atmosphere are enhanced over the warmer SSTs and reduced over the colder SSTs; latent heat fluxes are about twice the sensible heat fluxes. The anomaly amplitudes in the response, however, are not symmetric, with differences over the warm anomaly being much larger, especially for the latent heat fluxes ( 3 times as strong).

This asymmetry was not predicted by the idealized FGS model: it may be due to a more unstable, and thus turbulent, boundary layer on the front's warm side. Another contributing effect may be the nonlinearity of the Clausius-Clapeyron relation between surface air temperature and saturation mixing ratio: the increase in the latter over a warm SST anomaly is greater than the corresponding decrease over a cold anomaly. This effect is reinforced in our case because the cold anomaly is already on top of a colder SST.

The combined effect is, therefore, stronger evaporation in the STR simulation and results in a narrow band of enhanced precipitation along the Gulf Stream front (Fig. 2b), as found also by Minobe et al. (2008). The precipitation increase is very large, essentially doubling the precipitation of the CTL run.

\section{b. Regional circulation}

Latitude-height cross sections of STR-CTL differences across the SST front are shown in Fig. 3a. Warm temperature anomalies are not as strong as the cold ones, but extend over a greater height. This is consistent with a deeper MABL on the front's warm side. The temperature differences in the MABL are also shifted-especially for warm anomalies-by about $1^{\circ}$ to the south relative to the underlying SST differences (shown in Fig. 3b), probably as a result of advection by the northwesterly surface winds.

The cross-front anomalous circulation shows strong rising motion of about $0.1 \mathrm{~Pa} \mathrm{~s}^{-1}$ above the warm MABL temperature anomaly, extending into the troposphere to 
(a) Cross-front circulation

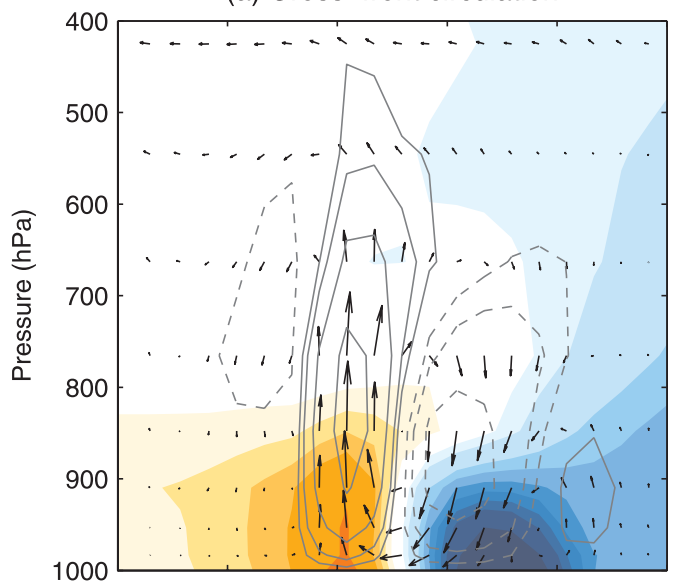

(b) SST profile

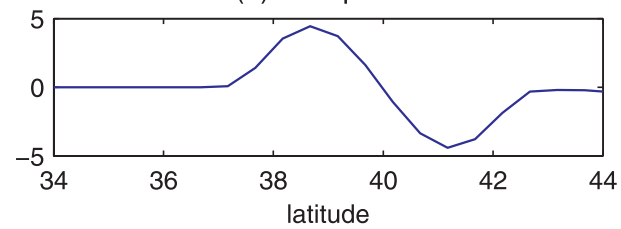

FIG. 3. Latitude-height cross section of the time-mean STR CTL differences. The fields are averaged between $75^{\circ}$ and $50^{\circ} \mathrm{W}$, with a moving reference latitude that follows the frontal position; the latter position is indicated for $60^{\circ} \mathrm{W}$. (a) Temperature (color), vertical speed [contours at $(1,2,4,8$, and 12$) \times 10^{2} \mathrm{~Pa} \mathrm{~s}^{-1}$; positive values indicate upward motion], and cross-front circulation (arrows); the arrows are scaled so that the apparent divergence matches the real one. (b) SST profile across the front.

about $500 \mathrm{hPa}$. The compensating subsidence over the cold anomaly is wider but weaker and shallower. Smaller differences in vertical motion are observed on both sides of the main cell, as suggested by the Laplacian of the temperature in Eq. (1). Total mean vertical velocities above the front have a similar upward extension in both simulations, but are stronger and narrower in the STR experiment (not shown). The anomalous circulation is closed by horizontal motion that reaches $1 \mathrm{~m} \mathrm{~s}^{-1}$ close to the surface. The maximum cross-front velocities are not collocated with the strongest SST gradient anomaly but with the strongest MABL temperature gradient-a consequence of the shift in MABL temperature anomalies (Small et al. 2008).

Changes in the alongfront velocity are shown in Fig. 4a. The vertical shear is enhanced over the cold SST anomaly, and reduced over the warm anomaly, possibly reflecting changes in MABL turbulence and stratification. At the surface, however, the mean winds are essentially cross front: they only start to follow the alongfront direction above $850 \mathrm{hPa}$. The strong surface anomaly near $40^{\circ} \mathrm{N}$ is probably due to pressure-driven, geostrophically balanced flow, following the temperature gradient with low SST and high pressure on its right.

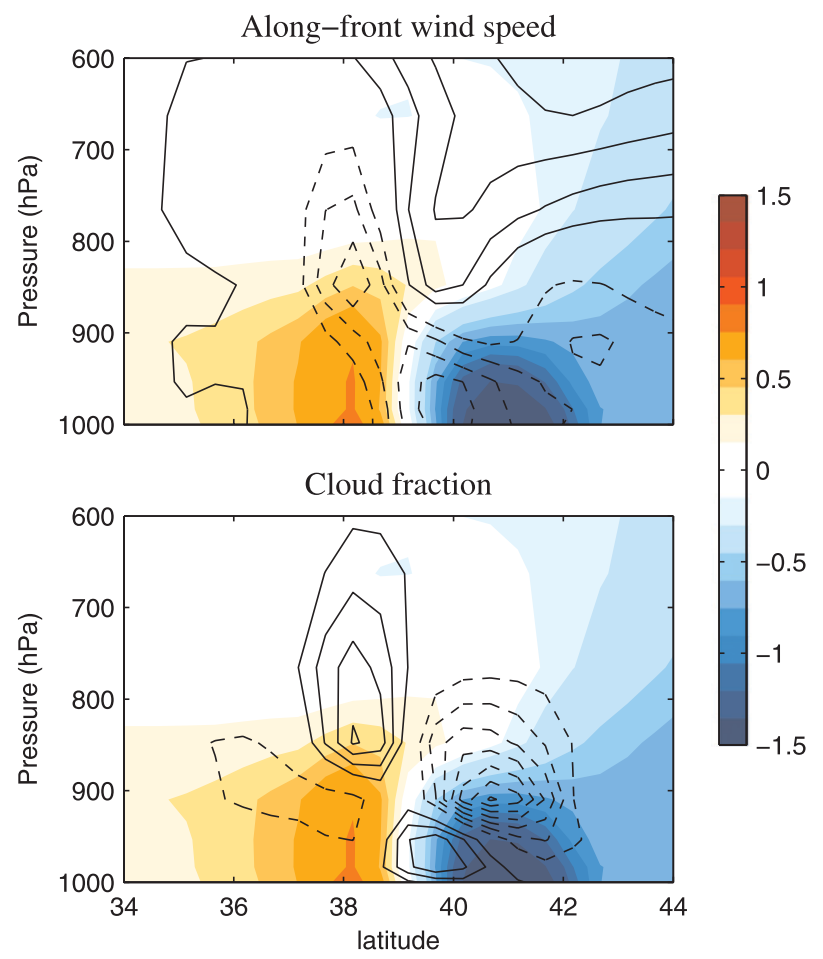

FIG. 4. As in Fig. 3, but with (a) contours showing differences in the alongfront wind speed (contour interval $0.2 \mathrm{~m} \mathrm{~s}^{-1}$ ) and (b) cloud fraction (interval 0.02).

Changes in the boundary layer structure are coupled with changes in cloud cover (Fig. 4b). Over the cold anomaly, where the MABL is stabler, a decrease of low clouds is observed around $850 \mathrm{hPa}$, whereas fog increases at the surface over the front. Low clouds also decrease slightly over the warm anomaly but midlevel clouds increase significantly because of enhanced convective rainfall. Similar effects were observed by Tokinaga et al. (2005) over the Kuroshio.

\section{Evaluation of the FGS mechanisms}

We now try to evaluate whether the FGS mechanisms embodied in Eq. (1) here provide an accurate explanation of the atmospheric flow's response to strong SST gradients. We first derive an equivalent relation from the MABL model of FGS(a) in terms of variables that are more readily calculated from the GCM fields. By taking the curl of their Eq. (3) and setting $z=0$, one obtains

$$
\nabla^{2} P_{\mathrm{SL}}=a \zeta_{850}-b \nabla^{2} T_{\mathrm{BL}}
$$

We will be mainly interested in the three key variables that appear in this equation: (i) the Laplacian of $P_{\text {SL }}$, the sea level pressure (SLP); (ii) $\zeta_{850}$, the relative vorticity at $850 \mathrm{hPa}$; and (iii) the Laplacian of the 
TABLE 1. Statistical relationships in the CTL and STR simulations over the Gulf Stream region $\left(35^{\circ}-47^{\circ} \mathrm{N}, 80^{\circ}-40^{\circ} \mathrm{W}\right)$. The first two rows give regression slopes of the Laplacian of the SLP on the Laplacian of the boundary layer temperature $\left(\mathrm{Pa} \mathrm{K}^{-1}\right)$ and on the 850-hPa vorticity $\left(\mathrm{kg} \mathrm{m}^{-3} \mathrm{~s}^{-1}\right)$. The bottom two rows give area-weighted spatial correlations between the same variables. Values are given for the long-term-mean and (in parentheses) for the 10-day-mean anomalies.

\begin{tabular}{llcr}
\hline \hline \multicolumn{1}{c}{$\nabla^{2} P_{\mathrm{SL}}:$} & & $\mathrm{CTL}$ & \multicolumn{1}{c}{ STR } \\
\hline Regression on & $\nabla^{2} T_{\mathrm{BL}}$ & $-45(-49)$ & $-41(-46)$ \\
& $\zeta_{850}$ & $1.1 \times 10^{-4}\left(1.0 \times 10^{-4}\right)$ & $-7.9 \times 10^{-5}\left(6.8 \times 10^{-5}\right)$ \\
Correlation with & $\nabla^{2} T_{\mathrm{BL}}$ & $-0.84(-0.57)$ & $-0.91(-0.59)$ \\
& $\zeta_{850}$ & $0.15(0.51)$ & $-0.34(0.31)$ \\
\hline
\end{tabular}

MABL temperature $T_{\mathrm{BL}}$. In the FGS model, $a=\rho_{0} f$ with the mean density $\rho_{0}=1 \mathrm{~kg} \mathrm{~m}^{-3}$ and the Coriolis parameter $f \simeq 10^{-4} \mathrm{~s}^{-1}$ at $40^{\circ} \mathrm{N}$, and $b=\rho_{0} g H_{e} / \theta_{0} \simeq$ $50 \mathrm{~m}^{2} \mathrm{~K}^{-1} \mathrm{~s}^{-2}$, with $\theta_{0}=300 \mathrm{~K}$ and $H_{e}=1500 \mathrm{~m}$ at $850 \mathrm{hPa}$.

We then compute long-term means of the variables in Eq. (3) over the CTL and STR simulations as well as 10-day block averages of the anomalies from this longterm mean. The 10-day window is long enough for the anomalies to be quasi-stationary, so that the diagnostic FGS equation applies, and still have a large enough number of samples. The mean response of the atmosphere to the SST field is thus removed from these anomalies, allowing us to isolate the impact of the freeatmosphere, mechanical term in Eqs. (1) and (3). Statistical relationships between these key variables appear in Table 1; binned scatterplots are shown in Fig. 5. The Gulf Stream region $\left(35^{\circ}-47^{\circ} \mathrm{N}, 80^{\circ}-40^{\circ} \mathrm{W}\right)$ is used in all these calculations.

The negative slope of the scatterplot between the vertical velocity $\omega_{850}$ at the top of the boundary layer and the Laplacian $\nabla^{2} P_{\mathrm{SL}}$ of the surface pressure (Figs. $5 \mathrm{a}, \mathrm{b})$ is consistent with the observed link between $\nabla^{2} P_{\mathrm{SL}}$ and surface convergence, which will in turn cause ascent. The regression slopes are roughly the same in both simulations, as well as for the long-term means and the anomalies.

The boundary layer temperature $T_{\mathrm{BL}}$ is defined in the GCM as the mass-weighted average between the surface and $850 \mathrm{hPa}$. Taking the Laplacian of $T_{\mathrm{BL}}$ instead of $\nabla^{2}$ (SST) improves the correlation with $\nabla^{2} P_{\mathrm{SL}}$ from 0.5 to 0.84 (Table 1); as noted in section 3 , the small-scale anomalies in $T_{\mathrm{BL}}$ are shifted downstream compared to the SST field by the cross-front winds. The MABL temperature field still has a large variance even after removing the long-term mean, probably because of advection by the anomalous circulation. The regression slope $s$ of $\nabla^{2} P_{\mathrm{SL}}$ versus $\nabla^{2} T_{\mathrm{BL}}$ in Figs. $5 \mathrm{c}$, d is again similar for the anomalies and the long-term means, and for both simulations, with a range of values of $s=-45 \pm$ $4 \mathrm{~Pa} \mathrm{~K}^{-1}$ (Table 1). A good correlation between the Laplacian of $T_{\mathrm{BL}}$ and surface wind convergence was also noted in satellite data (Shimada and Minobe 2011).
The 10-day-mean anomalies of the relative vorticity $\zeta_{850}$ at the $850-\mathrm{hPa}$ level have a positive correlation with $\nabla^{2} P_{\mathrm{SL}}$, which is also evident on the scatterplots of Figs. $5 \mathrm{e}$,f with regression slopes $s=8.4 \pm 1.6 \times 10^{-5} \mathrm{~Pa} \mathrm{~m}^{-2} \mathrm{~s}$ (Table 1). These slopes are consistent with a positive vorticity anomaly above the MABL leading to an SLP minimum below and to Ekman pumping, according to the effect of the mechanical component in FGS(a,b).

The vorticity $\zeta_{850}$ correlates less well with $\nabla^{2} P_{\mathrm{SL}}$ when long-term means are considered, especially in the STR simulation (Fig. 5). In the latter case, $\zeta_{850}$ is less representative of the circulation in the free atmosphere, since it also includes a component that is associated with a response to the thermal forcing: a warm $T_{\mathrm{BL}}$ anomaly will lead through hydrostatic balance to a low in the SLP field and thus to a positive $\nabla^{2} P_{\mathrm{SL}}$. This in turn will cause surface convergence, ascent, and hence a negative increment to the vorticity in the free troposphere.

This thermal forcing becomes dominant in the case of the STR simulation, as the SST gradients are large and the vorticity of the mean circulation is not as strong as for 10-day-mean anomalies. Because of this effect, the correlation between $\nabla^{2} P_{\mathrm{SL}}$ and $\zeta_{850}$ becomes negative, but this modified correlation reflects merely the dominance of the thermal forcing in this particular case rather than a departure from the FGS theory.

The values for the coefficients $a$ and $b$ in Eq. (3) obtained by using the regression slopes from Fig. 5 are therefore in general quite comparable in magnitude to the FGS estimates. One just has to exercise care and remove the mean response of the vorticity to the SST front in order to obtain a good estimate of the mechanical component $a$. A different check of the FGS values is to look for coefficients $a$ and $b$ that optimize the correlation of the right-hand side of Eq. (3) with $\nabla^{2} P_{\mathrm{SL}}$. This yields the same $a / b$ ratio, with variations of about $15 \%$, whether considering long-term means or anomalies, including in the STR simulation.

\section{Conclusions}

In this paper, we studied the atmospheric impact of realistically large, but small-scale, SST gradients that 
(a)

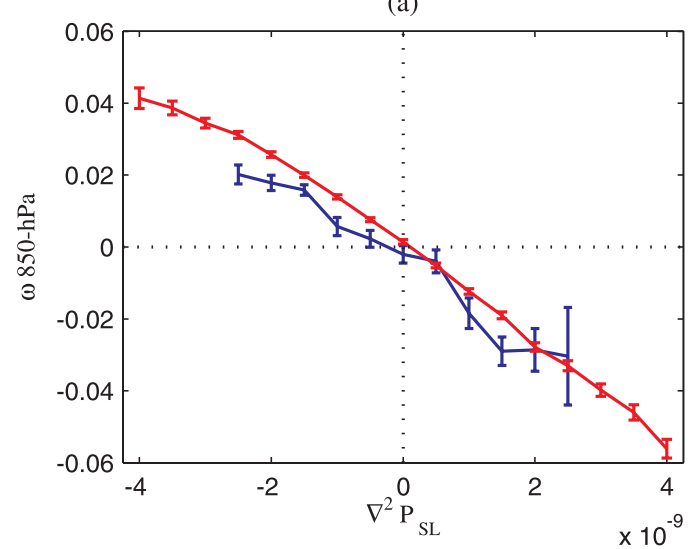

(c)

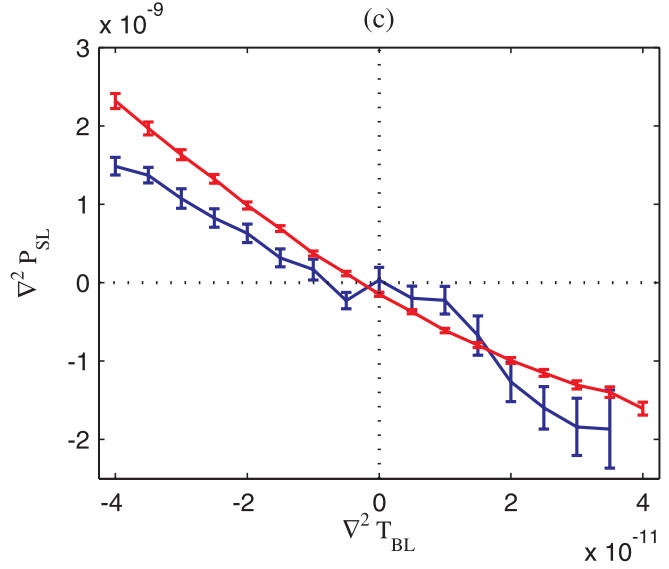

(e)

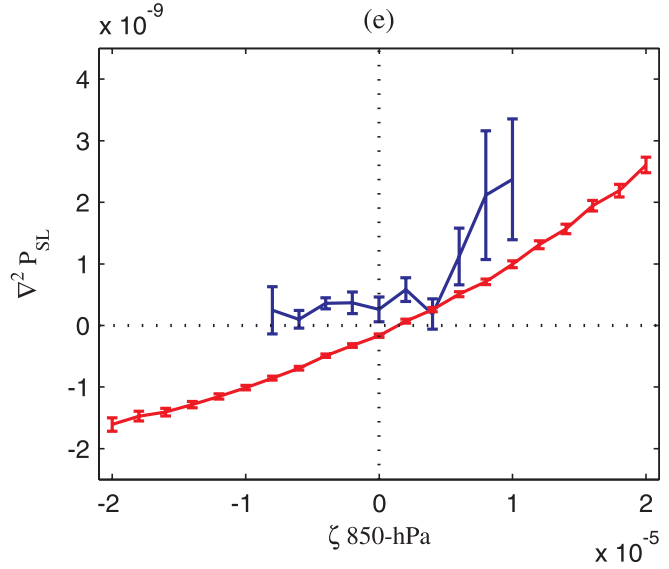

(b)

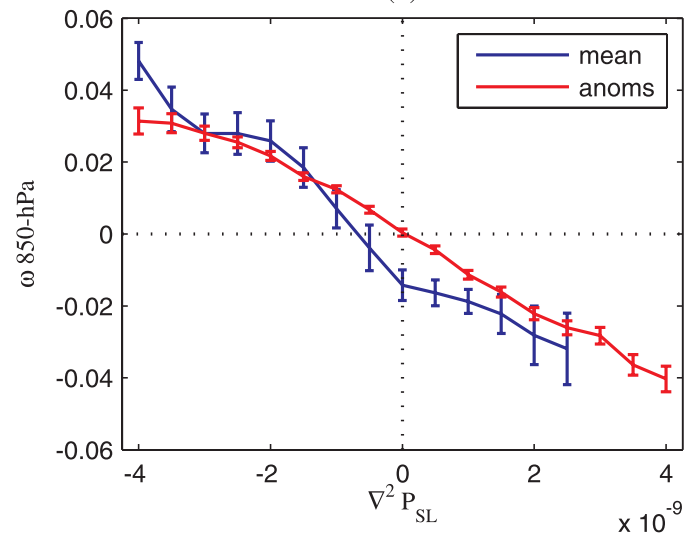

(d)

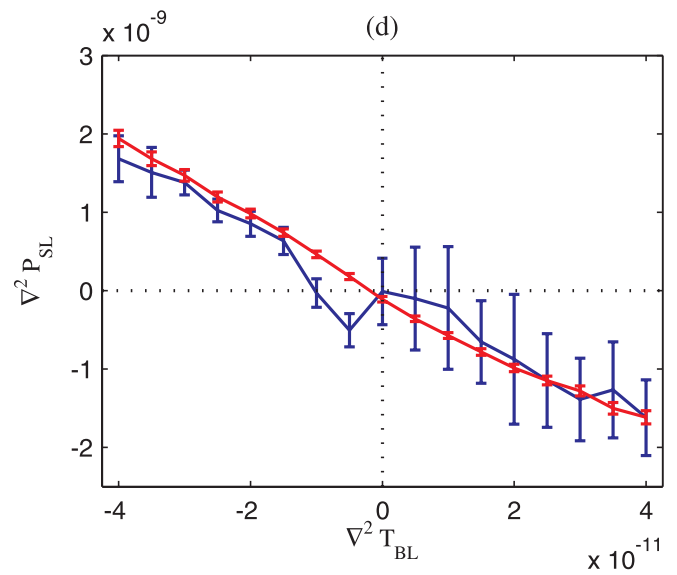

(f)

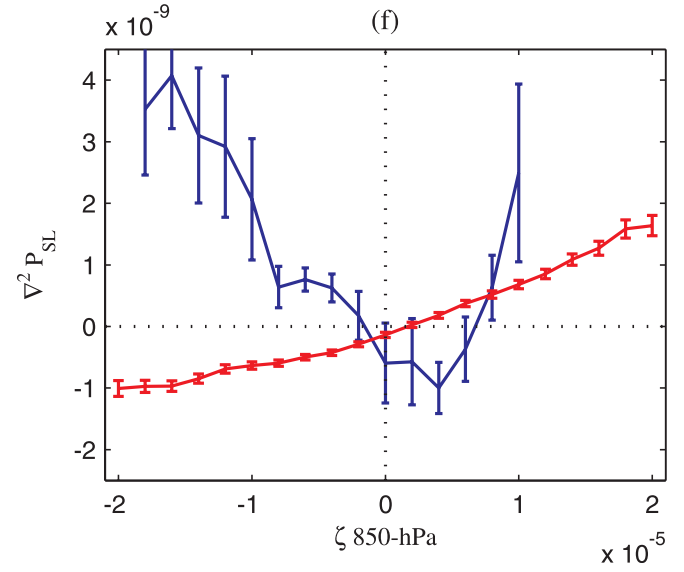

FIG. 5. Binned scatterplots of key variables over the Gulf Stream region $\left(35^{\circ}-47^{\circ} \mathrm{N}, 80^{\circ}-40^{\circ} \mathrm{W}\right)$ in the (left) CTL and (right) STR simulations. Long-term-mean fields are in blue, and 10-day-mean anomalies are in red. (a),(b) $850-\mathrm{hPa}$ vertical velocity $\omega_{850}\left(\mathrm{~Pa} \mathrm{~s}^{-1}\right)$ and Laplacian of SLP $\nabla^{2} P_{\mathrm{SL}}\left(\mathrm{Pa} \mathrm{m}^{-2}\right),(\mathrm{c}),(\mathrm{d}) \nabla^{2} P_{\mathrm{SL}}$ and Laplacian of boundary layer temperature $\nabla^{2} T_{\mathrm{BL}}\left(\mathrm{K} \mathrm{m}^{-2}\right)$, and (e),(f) $\nabla^{2} P_{\mathrm{SL}}$ and 850 -hPa vorticity $\zeta_{850}\left(\mathrm{~s}^{-1}\right)$. The vertical bars show the $95 \%$ confidence interval.

reinforce the climatological Gulf Stream front. Two simulations were carried out using the GCM LMD-Z with a $50-\mathrm{km}$ zoom over the western North Atlantic $\left(30^{\circ}-50^{\circ} \mathrm{N}, 75^{\circ}-55^{\circ} \mathrm{W}\right)$ : one with climatological SSTs, called CTL, and the other with an idealized enhancement of the SST front, called STR. The circulation in the GCM's marine atmospheric boundary layer (MABL) is well predicted, following FGS(a,b), by Eq. (1), which summarizes the three-way balance between surface pressure gradients, surface friction, and the Coriolis force.

Our GCM study—using full dynamics and physics, as well as increased resolution, as recommended by 
FGS(a,b) - thus validates FGS's theoretical predictions and leads, furthermore, to the following conclusions:

- The mean response to a symmetrically enhanced SST front is strongly asymmetric-heat flux differences, especially in latent heat, are larger on the warm side, while the vertical velocity response there is stronger and reaches higher in the free troposphere.

- The MABL structure also changes, with enhanced stability on the cold side, and reduced stability on the warm side; this leads to opposite changes in the vertical wind shear and the cloudiness, and the boundary layer grows higher on the warm side.

- The atmospheric response, as measured by the Laplacian of sea level pressure, is best correlated with the Laplacian of the temperature averaged over the MABL, not with the SST or near-surface temperature: the mean MABL temperature pattern is shifted downstream with respect to the SST front by the mean crossfrontal winds; this shift changes the phase relation between the SST field and surface winds. The rapidly varying free-atmospheric winds will thus generate a variable atmospheric response to the SST field, even when the latter is stationary or very slowly varying.

- The long-term-mean response of the atmosphere is dominated by the thermal gradients. For periods of 10 days or less, however, pumping in the MABL by vorticity anomalies is much stronger, and the thermal and mechanical terms in Eq. (1) are of equal importance.

Acknowledgments. It is a pleasure to thank L. Li, F. Lott, R. Plougonwen, and especially J. D. Neelin for useful discussions and suggestions. Constructive comments by three anonymous reviewers have helped improve the presentation. This work was supported by a scholarship of the European Commissions Integrated Project ENSEMBLES to S. Brachet, by U.S. Department of Energy Grants DE-FG02-07ER64439 and DE-FG02-02ER63413 (Y.F., M.G., and E.S.), and by NSF Grant DMS-1049253 (M.G.).

\section{REFERENCES}

Bryan, F. O., R. Tomas, J. M. Dennis, D. B. Chelton, N. G. Loeb, and J. L. McClean, 2010: Frontal scale air-sea interaction in highresolution coupled climate models. J. Climate, 23, 6277-6291.

Feliks, Y., M. Ghil, and E. Simonnet, 2004: Low-frequency variability in the midlatitude atmosphere induced by an oceanic thermal front. J. Atmos. Sci., 61, 961-981.
,-- , and -2007 : Low-frequency variability in the midlatitude baroclinic atmosphere induced by an oceanic thermal front. J. Atmos. Sci., 64, 97-116.

— — - and A. W. Robertson, 2011: The atmospheric circulation over the North Atlantic as induced by the SST field. J. Climate, 24, 522-542.

Hourdin, F., and Coauthors, 2006: The LMDZ4 general circulation model: climate performance and sensitivity to parametrized physics with emphasis on tropical convection. Climate Dyn., 27, 787-813, doi:10.1007/s00382-006-0158-0.

Kelly, K. A., R. J. Small, R. M. Samelson, B. Qiu, T. M. Joyce, Y.-O. Kwon, and M. F. Cronin, 2010: Western boundary currents and frontal air-sea interaction: Gulf Stream and Kuroshio extension. J. Climate, 23, 5644-5667.

Kwon, Y.-O., M. A. Alexander, N. A. Bond, C. Frankignoul, H. Nakamura, B. Qiu, and L. A. Thompson, 2010: Role of Gulf Stream and Kuroshio-Oyashio systems in large-scale atmosphere-ocean interaction: A review. J. Climate, 23, 3249-3281.

Lindzen, R. S., and S. Nigam, 1987: On the role of sea surface temperature gradients in forcing low-level winds and convergence in the tropics. J. Atmos. Sci., 44, 2418-2436.

Minobe, S., A. Kuwano-Yoshida, N. Komori, S. P. Xie, and R. J. Small, 2008: Influence of the Gulf Stream on the troposphere. Nature, 452, 206-209.

Nakamura, M., and S. Yamane, 2009: Dominant anomaly patterns in the near-surface baroclinicity and accompanying anomalies in the atmosphere and oceans. Part I: North Atlantic basin. J. Climate, 22, 880-904.

O’Neill, L. W., S. K. Esbensen, N. Thum, R. M. Samelson, and D. B. Chelton, 2010: Dynamical analysis of the boundary layer and surface wind responses to mesoscale SST perturbations. J. Climate, 23, 559-581.

Shimada, T., and S. Minobe, 2011: Global analysis of the pressure adjustment mechanism over sea surface temperature fronts using AIRS/Aqua data. Geophys. Res. Lett., 38, L06704, doi:10.1029/2010GL046625.

Small, R. J., S. P. DeSzoeke, S. P. Xie, L. O’Neill, H. Seo, Q. Song, and P. Cornillon, 2008: Air-sea interaction over ocean fronts and eddies. Dyn. Atmos. Oceans, 45 (3-4), 274-319.

Taguchi, B., H. Nakamura, M. Nonaka, and S.-P. Xie, 2009: Influences of the Kuroshio/Oyashio extensions on air-sea heat exchanges and storm-track activity as revealed in regional atmospheric model simulations for the 2003/04 cold season. J. Climate, 22, 6536-6560.

Tokinaga, H., Y. Tanimoto, and S.-P. Xie, 2005: SST-induced surface wind variations over the Brazil-Malvinas confluence: Satellite and in situ observations. J. Climate, 18, 34703482.

Wallace, J. M., T. P. Mitchell, and C. Deser, 1989: The influence of sea-surface temperature on surface wind in the eastern equatorial Pacific: Seasonal and interannual variability. J. Climate, 2, 1492-1499.

Warner, T. T., M. N. Lakhtakia, J. D. Doyle, and R. A. Pearson, 1990: Marine atmospheric boundary layer circulations forced by Gulf Stream sea surface temperature gradients. Mon. Wea. Rev., 118, 309-323. 